\title{
Fitness to Practise cases predicted to rise slightly in 2019
}

The number of Fitness to Practise (FtP) cases raised with the dental regulator the General Dental Council (GDC) is predicted to rise to around 1,800 in 2019 , up from 1,642 in 2018.

The predictions were made in the newly published Moving Upstream report ${ }^{1}$ discussed at the GDC conference held on 30 January 2019 in Birmingham.

The report says that, based on current trends and forecasts, 1,800 FtP cases would be received by the regulator this year, with roughly 250 of these cases typically going to a full hearing, compared with 224 in 2017 that were referred for prosecution.

In addition, the GDC expected to receive and complete around 5,000 first time applications, and forecast to complete just over 1,300 restorations.

The GDC said that in terms of absolute figures, the numbers of concerns raised had been falling over the past five years (it reached 3,107 cases in 2014, with the most dramatic decrease taking place over the past two years.

'It is likely that this has been, at least in part, as a consequence of changes to the way in which concerns are managed, including through the use of our signposting tool,' says the report.

This signposting tool was introduced to the GDC's website to advise people of their options if they had a concern about their dental care because previously many of the concerns sent to the GDC did not proceed beyond initial assessment due to the fact that they did not constitute a potential allegation of impaired fitness to practise.

'Since its introduction, fewer than $20 \%$ of people who use this tool go on to raise these concerns with the GDC, says the report. 'The remainder are directed elsewhere, where their concerns can be more effectively dealt with.

'We have, therefore, seen a measurable decline in the number of concerns being raised that are subsequently closed at the earliest stage. This suggests the tool is helping patients to better understand our role. Receiving fewer cases that we close at initial assessment also enables us to focus resource on those which are potentially more serious.'

The regulator argued that the process had been improving since its' Shifting the Balance agenda ${ }^{2}$ was published in January 2017, to seek to reform dental regulation and refocus fitness to practise to be clear about the serious nature of 'impaired fitness to practise' and ensuring that anything short of that was dealt with using alternative tools.

As a result of changes, the GDC's Initial Assessment Decision Group now met daily to consider any new concerns that had been raised in the preceding 24 hours, meaning the time taken to move cases through this first part of the process had reduced by nearly $70 \%$, from 12 days to under four.

Also, the time cases spent for those in the assessment stage had been reduced from 12 weeks to between eight to ten.

During the conference, GDC Chair Bill Moyes urged the audience to accept the fact that feedback and comments about dentistry were part of the modern world seen across all industries.

'Across all sectors of the economy, complaints and feedback have become a fact of life,' said Moyes. 'Look at Amazon, TripAdvisor, Airbnb and hundreds of other examples.

'Those most interested in providing the best service that they can - a principle that must surely be at the heart of healthcare treat complaints and feedback as free advice and as a mechanism for turning unhappy customers or patients into happy ones in the present, and improving services in the future.

'While the main beneficiary of this work is a better served public, there are clear benefits for the profession too. Embracing feedback and complaints and handling them expertly in the practice means fewer unnecessary issues coming to the GDC.

\section{References}

1. General Dental Council. Moving Upstream. 2019. Available at https://www.gdc-uk.org/about/whatwe-do/shifting-the-balance/moving-upstream (accessed February 2019).

2. General Dental Council. Shifting the balance: a better, fairer system of dental regulation. 2017. Available at https://www.gdc-uk.org/about/what-we-do/shifting-the-balance (accessed February 2019).
Here has been

an advertisement.

SPRINGERNATURE 